\title{
Emerging Communities of Practice
}

\author{
Martha McAlister \\ Camosun College
}

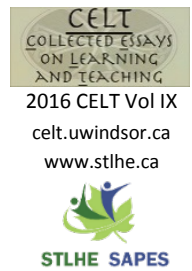

Communities of practice are emerging as an innovative approach to faculty development. While collaborative learning is becoming popular in the classroom, autonomy and individualism continue to dominate the culture of higher education for faculty. However, as we begin to recognize that old solutions to new problems are no longer effective, there is a growing desire for innovative engagement requiring the embrace of multiple perspectives. This takes the development of new habits of mind and discourse. For my dissertation, I engaged in a qualitative study with my colleagues where we experimented with generative approaches to dialogue in a community of practice. It became apparent that creating supportive, collegial spaces where we can explore beyond the edge of what we currently know can help us bridge across differences, harness the potential within diversity, and step into the emerging future. However, it also became apparent that this quality of dialogue is not easy.

\section{Introduction}

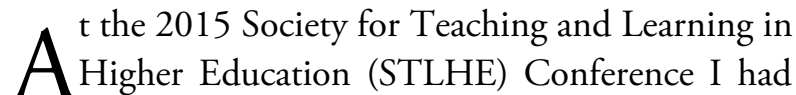
the opportunity to facilitate a dialogue based on my recent dissertation, "Dissonance and resonance in a community of practice" (McAlister, 2015). What follows is an account of my research, and then the ongoing process of co-creating communities of practice $(\mathrm{CoP})$ in a post-secondary environment. The dissertation research acted as a pilot project that synchronistically coincided with a campus-wide initiative to create a culture of CoPs. Lessons learned from the original research continue to ripple through the development of these dialogue groups.

As a college teacher, I regularly reflect on what makes classroom dynamics vibrant and engaging. I work hard to intentionally create a holding environment that supports and challenges my students at the edge of their development. I have come to recognize that the most successful classroom experiences involve dancing on a fine line between intention and emergence-between preconceived structure and immediacy. Tuning in to and being responsive to the lived intersubjective moment in the classroom has become a rich source of deep learning for me and my students. Eyes wide open, hearts pounding, awake, on the edge.

I have often wondered what it would be like for college faculty to create these kinds of holding environments with and for each other, intentionally designed to support and challenge us at our leading edge of learning and development. Would we be willing to risk the kind of vulnerability inherent in tuning in to the potential within each emerging moment? Eyes wide open, hearts pounding, awake, on the edge?

You know these kinds of collegial conversations. They most often occur by accident rather than by intention; at the water cooler, out at pub night, in-between meetings, or in passing down the hall. Or you attend an inspiring professional development event where you share a sense of synergy and momentum with colleagues. You feel energized through engaging in meaningful dialogue with coworkers who share a passion for their work. You say to each other, we should do this more often! Then, you go back into your siloed classroom and office, or to another meeting where eyes glaze over. The passion dissipates.

I decided to focus my dissertation on experimenting with creating a community of practice at my college utilizing generative approaches to dialogue. By generative, I mean dialogue that attends 
to the opportunity present in each emerging moment. Working with faculty, my intention was to focus farther upstream from the classroom where there is more potential to impact the broader college culture. While we are beginning to use collaborative and emergent approaches to learning and development in the classroom, we have yet to really embrace these concepts among ourselves.

\section{Complexity, Change, and Higher Education}

Throughout my doctoral journey, almost everything I read began with an urgent observation that the world is changing at a rapid rate, becoming ever more uncertain and complex. Kegan (1994) aptly describes how we are "in over our heads" and ill equipped to meet the current demands we are facing as a society. Sitting at the cross-roads of many of these pressures, is it any wonder anxiety is on the rise across colleges (Kadison \& DiGeronimo, 2004)? While post-secondary institutions scramble to respond, many initiatives fail to achieve their goals. Innovation can come across as fragmented and add to the hectic pace unless well-grounded in meaning and purpose (Fullan, 2001). Reacting from a place of anxiety can limit our openness to learning (Cranton, 1994), as we are more likely to revert to habitual lower order functioning (Senge, Scharmer, Jaworski, \& Flowers, 2004).

As the rate of change increases, and work becomes more fragmented and specialized, effective communication within and between organizations becomes more challenging, yet even more essential. Schein (2004) sees that organizational change is driven from the inside out, in the sense that individual beliefs shape group norms that create organizational structures. Dialogue can provide an interface between individual beliefs and group norms, and is often seen as central to any organizational change process (Senge, 1990). It has the potential to bridge fragmented subcultures and help us to respond more effectively to complexity.

\section{Dialogue and Communities of Practice}

In conventional organizational discussions, we often enter with preconceived notions that we then actively defend, as we dissect opposing views. We can easily feel threatened by differing perspectives that trigger habitual fight, flight, or freeze behaviours. According to Bohm (1996) and Isaacs (2001), dialogue provides an opportunity to hold space for, and use the energy of difference for, collective creativity. Generative dialogue, or presencing (Scharmer, 2009), describes a process of actively letting go of preconceived notions, and attentively opening to the potential occurring in the present moment. It is a contemplative practice that requires listening for emerging shared meaning (Gunnlaugson, 2007). It requires intra and interpersonal embodied awareness, which includes being able to recognize and surface the energetic tensions that are occurring within and between participants.

Communities of practice may be an ideal format for experimenting with thoughtful approaches to faculty dialogue. A community of practice (CoP) describes a group of people with a common passion for what they do, who want to interact regularly to learn how to do it better (Wenger, 1998). Some important principles include deep mutual respect, shared purpose, trust, a culture of openness, and collective responsibility. These conversations have been shown to have a positive influence on teacher effectiveness and student learning (MacDonald, 2001). Group learning can foster reflection, trigger new perspectives, and provide social support (Lassonde \& Israel 2010). CoPs may increase the potential for the current culture of silos in higher education to shift towards greater collaboration (Dees et al., 2009).

However, unless there is a clear understanding of the risks involved with confronting differing views, and a willingness to engage with the edge of our vulnerability, these CoPs will fall short of their full potential. Those of us working in higher education must wrestle with a diversity of pressures and challenges. There are no quick and easy answers, and it calls for dedication and intentionality. 
Exploring complex questions requires time and space for the answers to emerge (Palmer \& Zajonc, 2010). We are more open to risking growth when we feel affirmed in a community of support. But there has been little attention given to how we create faculty holding environments for transformational change.

\section{The Study}

Over the period of one semester, I met regularly with a small group of faculty to experiment with dialogic approaches within a community of practice. I used a participatory action inquiry methodology. With action inquiry, research and practice are integrated into each emerging moment (Torbert \& Associates, 2004). The content of our conversations developed collaboratively from the group, and then I summarized themes and observations that I iteratively brought back into each consecutive meeting. The content of our conversations focused on such topics as evaluation and feedback between students and teachers, whereas my primary interest for this qualitative study was about our process. I was curious about the moment-to-moment actions and inquiries that occurred and how that helped to shape our dialogue. At the end of our seven sessions, I gathered my observations into coherent themes and invited input on the final report from participants.

\section{Findings}

\section{Dialogue is provocative}

One of the key findings from this study is that dialogue can be very provocative. Kegan (2000) makes a distinction between transformational and informational learning, and participants expressed some interest in both of these as we articulated different kinds of goals for our conversations (McAlister, 2015). However, it became clear that even the most seemingly technical kinds of informational conversation can be unwittingly provocative, and, therefore, threaten transformation.
Interestingly, participants readily discussed and acknowledged that conversations and content in our classes can be provocative for students (McAlister, 2015), which we generally saw as a good thing. But we recognized that when there is resistance to transformational learning as a goal, it can act as a barrier and block the creative potential in a group.

\section{Dissonance and resonance are useful sources of knowledge}

Following from the recognition that all dialogue has the potential to be provocative is the observation that provocation is physically felt in the body. There is a felt sense of either dissonance or resonance accompanying any dialogue that provides it with physical and emotional texture. Whether it is an attuned feeling of recognition, acknowledgement and belonging, or the agitated feeling often associated with a fight, flight, or freeze response, our embodied sensations in the present moment can provide a rich source of information.

Early in my research, I began to recognize the power of this felt response, and got curious about how leaning into it might enhance our learning potential. It became apparent to me that the places of dissonance and resonance in our conversation held a lot of potential for further exploration. For example, when we expressed differing perspectives about providing students with subjective and objective feedback, our positions held some emotional charge, while at the same time we worked to try and understand each other's views by asking curious questions.

Our group attempted to use generative approaches to dialogue by suspending preconceived notions and surfacing present dynamics, but most often we fell back into old habits and patterns of relating (McAlister, 2015). Giving voice to immediate feelings of dissonance required courage and trust. Some participants felt that it distracted the group from focusing on the content of our conversation (McAlister, 2015). On the occasions when someone acknowledged a felt tension, a sense of uncertainty, space, and possibility opened up. We 
recognized that a willingness to not know and to sit with the discomfort was important (McAlister, 2015).

\section{Tuning in to embodied awareness can help us bridge across difference}

In higher education, as in most postmodern contexts, we are faced with the challenge and gift of diversity. At my college, we espouse the belief that diversity is not just a reality, but an asset. A systems perspective helps us be more cognizant of our interdependence with all of existence. However, bridging the gap across difference can be difficult, particularly if we are not practiced at recognizing and suspending our own perspective. Developing an empathetic connection can enhance our ability to be open to diverse perspectives (Yorks \& Kasls, 2002), but requires the development of social-emotional intelligence. When opinions differ, it is worth stepping back and recognizing how our fundamental beliefs and values are at work.

Our research group appeared fairly homogenous on the surface. Coming from a similar socio-economic and educational background, with shared assumptions stemming from our mutual discipline, we had a lot in common. However, even in this group there were distinctions that began to come to the surface as we became more comfortable with revealing our beliefs and values. These distinctions will not come to the surface in a productive way if someone feels threatened, defensive, or not understood.

In the culture of higher education, we are accustomed to using our critical reasoning and rational intelligence to think our way through the challenges we encounter. However, trying to separate head from heart overlooks a valuable source of knowledge. When we avoid what is emerging in the present moment within the group, the chance to harness that energy for co-creating alternative futures gets lost. Tuning in to the embodied sense of dissonance can provide a first step toward resonance, and a more collaborative and innovative outcome.

\section{Vulnerability is inevitable at the edge of our comfort zone}

I began to notice how vulnerable I felt, even though I knew I was with a group of supportive colleagues. Normally, feeling vulnerable would provoke a defensive and habitual response, but instead I took this as a good sign! It meant I felt supported enough to risk going below the surface of our conversation. I wanted to explore beyond the edge of our current knowing, or, as Torbert \& Associates (2004) calls it, listen into the dark.

It was hard for us to determine if someone was feeling uncomfortable unless we were paying close attention and making room for it. Comparing it to what happens in the class, we recognized that it is difficult to know when a student may be triggered by something that is occurring, and that while we cannot guard against it, we can be empathetic, acknowledging the emotional reality of a learning process. We are accustomed to creating learning opportunities where our students are challenged to step into unknown territory, which is inevitably a vulnerable feeling.

Participants expressed how important it was to feel safe in order to take risks in our dialogue (McAlister, 2015). However, I came to understand that safety was not only impossible, but undesirable. The only truly safe path is one where we cocoon ourselves into familiar, unchanging environments that threaten us with stagnation. In our diverse and ever changing world, this is no longer a realistic option. Instead of safety, we discussed developing a supportive environment where participants felt willing to be more vulnerable. My experience was that I felt encouraged to try and speak from my most authentic self, and to listen deeply for the authentic voice of my colleagues. 


\section{Tips for Constructing a Transformative CoP}

\section{Practice mindfulness}

Generative dialogue requires the ability to suspend preconceived notions and be open to what is emerging in the moment. Mindfulness practice, such as meditation or other contemplative approaches, can help to foster that ability. Kabat-Zinn (1990) defines mindfulness as the intentional cultivation of nonjudgmental moment-to-moment awareness. In the research CoP, we experimented with incorporating a brief period of meditation into the meeting structure. This had mixed results, as not all participants were equally comfortable with it (McAlister, 2015). How a mindfulness approach is utilized will depend on the particular group and what works for them.

\section{Attend to power dynamics}

Nothing will shut down open dialogue more quickly than the presence of (or perception of) a power imbalance between participants. In a post-secondary CoP context, this imbalance could take the form of differing positional authority, status as continuing or term faculty, seniority, or belonging to different unions. It also might be a felt sense of differing power based on gender, ethnicity, or perception of selfefficacy. Differing power is not inherently bad, nor can it necessarily be avoided. It may, in fact, be an additional juicy source of dissonance with which to work. But it needs to be surfaced, acknowledged, and given attention in order to help create an environment that all participants feel equally willing and able to be vulnerable.

In the research CoP, some participants felt unable or unwilling to speak at times because of a feeling they might be negatively judged (McAlister, 2015). We acknowledged that although we need to be sensitive to what might be making each other feel vulnerable, we cannot always know or avoid what may cause someone else to feel uncomfortable. Power, real and perceived, is one of the great complexities with which we need to practice working in diverse learning environments.

\section{Intentionally thicken resonance and dissonance}

Our group readily acknowledged and practiced the value in a strength-based approach to working together. We took time to give voice to what we appreciated about our working environment and about each other. Intentionally thickening resonance can mean bringing some of that appreciative voice into the emerging moment by noticing when there is a felt sense of connection, agreement, or feeling understood. Beyond pat praise, it requires recognition of an embodied feeling. When someone in our group made this kind of observation in the moment, it had the effect of thickening and strengthening that felt sense and making it into more of a shared experience.

With a strong common belief in the value of a strength-based approach, we may tend to shy away from leaning into experiences of dissonance. However, giving voice to uncomfortable feelings that arise can create an opportunity for something different to occur. We may feel an urge to solve it quickly by engaging in our old familiar habits of dealing with conflict, but if we are willing to slow down, step back, and stay with the fullness of the experience, we can learn to welcome dissonance as a gift. Participants in our group voiced a feeling of dissonance on a couple of occasions, and it had a powerful impact on the quality of conversation, though we seemed to avoid staying there long (McAlister, 2015).

Generative dialogue can be used to focus on what is emerging. This involves asking open-ended questions, giving voice to what you are sensing and noticing, being comfortable with silence, avoiding the urge to rush to a solution, and becoming more curious about what you do not already know. Using the present-continuous tense (e.g., "I am noticing...; I am wondering...; I am feeling...") is a great tool to practice immediacy. 


\section{Balance support and challenge}

We know how important it is in our teaching to provide ample supportive feedback to our students to help them flourish. A strength-based, appreciative approach means we recognize how vital it is for learners to feel validated. The same is true in faculty learning contexts. When it comes to challenge, it is important for colleagues participating in a $\mathrm{CoP}$ to have agreement about the kind of group they want from the outset. With a foundation of trust, people are more willing to view conflict as an opportunity for growth (Cranton, 1994). Too much challenge early in the process can cause defensiveness and feel overwhelming (Daloz, 2000; Palmer \& Zajonc, 2010). Challenge can take the form of willingness to voice a difference of opinion or willingness to nonjudgmentally provide feedback about what you notice in someone else's behaviour. It is essential for this to occur within a context of trust and mutual respect.

\section{Balance structure and emergence}

According to Kegan (1994), a good holding environment serves three functions that he calls confirming, contradicting, and continuing. The container itself must be capable of evolving and getting stronger and also more permeable (Gunnlaugson, 2009). When designing the container of a CoP, it is worth aiming for the minimum structure that permits the maximum emergence. Good structure includes developing some shared core agreements about how the group wants to function together. What is our commitment? What is our focus? How will we make decisions or deal with conflict? How will leadership occur? These parameters help provide the necessary support that allow participants to engage more fully at their leading edge. Too much structure and the group will suffocate. Not enough structure and the group may experience chaos and confusion. Our research group spent the first meeting establishing some common ground for how we wanted to be together. In a group that repeatedly meets over a longer period, this may need to be revisited from time to time.

\section{Conclusion and Implications}

Core to my findings is the recognition of the relational and emergent nature of reality. Even in a group of relatively homogenous, likeminded, caring colleagues, there is great diversity. Even a seemingly technical conversation about student evaluation can provoke a transformative learning opportunity. More than anything else, my research left me with the conviction that when it comes to transformative learning, if you can't get out of it you might as well get into it!

These dialogues continue to unfold. Since completing my dissertation research, I have been working with our Teaching and Learning Centre to help create communities of practice at our college. To date, there are ten groups now meeting regularly. I have presented my findings in various formats to various groups. I continue to read and engage in dialogues that support my ongoing, evolving sense of the implications of deep dialogue for faculty development. At the 2015 STLHE Conference, a small group of us met outside on a beautiful Vancouver day, where I facilitated a conversation. Rather than just talking about CoPs, we actively took up the practice of generative dialogue. One participant mentioned that of all the workshops she had attended at the conference, the moments that will stay with her the most were the spontaneous conversations over lunch, and our mini enactment of a CoP.

I have found that faculty are hungry for meaningful conversation about what is most important to them in their work. While it seems like an insurmountable barrier to find the time, once there, participants report feeling invigorated. However, a challenge continues to be how best to create structures that support emergence.

Minimally, the CoP groups I have helped to establish have a few common structures and characteristics that seem to be helpful. We always start with a brief round circle check-in as a way to become more present and intentional about our time together. We always end with a brief round circle check-out as a way to reflect on key learning and to enhance the sense of a shared experience. The 
principles of collective responsibility, strength-based focus, and establishing a culture of trust are expressed. The passion and interest in forming a $\mathrm{CoP}$ group comes from the faculty themselves, and I take the role of assisting in its development.

Finding time and getting people to make a commitment continues to be another key challenge. Building a solid foundation of trust takes time, and while many participants have readily expressed a rewarding sense of connection and felt group resonance with each other, most groups have not yet ventured far beyond the polite stage where conflicting perspectives and dissonance are rarely brought to the surface. On the occasions when there has been some tension, it has been difficult to make space to work with it productively. I see this as something that could evolve with time, if we hold the common intention and desire to more fully utilize the opportunity present in our diversity.

My work is to continue practicing from my emerging capabilities as a teacher within the classroom, and as a colleague within the various collaborative environments in which I find myself. Our college is currently actively pursuing strategies to enhance sustainability and interdisciplinary education. Our goal in higher education should be to prepare students to be engaged citizens in a global society, where recognition of our interdependence is essential for overall wellbeing. I feel strongly that in order to do this effectively, we must intentionally practice our interpersonal communication skills using the best of what is known to promote effective and creative collaboration. A siloed, competitive approach to education is no longer sufficient.

Collegial dialogue that is designed with a developmental framework, to assist us in stepping into the vulnerability of the emerging unknown, is not easy. It challenges us to set aside our habits of interaction and be willing to truly encounter each other with the fullness of our beings. In an ever more complex, diverse, and rapidly changing world, nothing seems more pressing than to slow down and learn how to engage with each other in dialogue.

\section{References}

Bohm, D. (1996). On dialogue. New York, NY: Routledge.

Cranton, P. (1994). Understanding and promoting transformative learning: A guide for educators of adults. San Francisco, CA: Jossey-Bass.

Daloz, L. (2000). Transformative learning for the common good. In J. Mezirow \& Associates (Eds.), Learning as transformation (pp.103123). San Francisco, CA: Jossey-Bass.

Dees, D. M., Zavota, G., Emens, S., Harper, M., Kan, K. H., Niesz, T., ... Hovhannisyan, G. (2009). Shifting professional identities: Reflections on a faculty learning community experience. Learning Communities Journal, 1(2), 49-73.

Fullan, M. (2001). The new meaning of educational change. Toronto, ON: Erwin.

Gunnlaugson, O. (2007). Shedding light on the underlying forms of transformative learning theory: Introducing three distinct categories of consciousness. Journal of Transformative Education, 5(2), 123-151.

Gunnlaugson, O. (2009). Establishing second person forms of contemplative education: An inquiry into four conceptions of intersubjectivity. Integral Review, 5(1), 2550.

Isaacs, W. (2001). Toward an action theory of dialogue. International Journal of Public Administration, 24(7-8), 709-748.

Kabat-Zinn, J. (1990). Full catastrophe living: Using the wisdom of your body and mind to face stress, pain, and illness. New York, NY: Delta.

Kadison, R., \& DiGeronimo, T. F. (2004). College of the overwhelmed: The campus mental health 
crisis and what to do about it. San Francisco, CA: Jossey-Bass.

Kegan, R. (1994). In over our heads: The mental demands of modern life. Cambridge, MA: Harvard University Press.

Kegan, R. (2000). What "form" transforms? In J. Mezirow \& Associates (Eds.), Learning as transformation (pp. 35-69). San Francisco, CA: Jossey-Bass.

Lassonde, C., \& Israel, S. (2010). Teacher collaboration for professional learning: Facilitating study, research, and inquiry communities. San Francisco, CA: Jossey-Bass.

MacDonald, I. (2001). The teaching community: Recreating university teaching. Teaching in Higher Education, 6(2), 153-167.

McAlister, M. (2015). Dissonance and resonance in a community of practice (Doctoral dissertation). Retrieved from ProQuest Dissertations \& Theses Database. (AAT 3685763).

Palmer, P. \& Zajonc, A. (2010). The heart of higher education: A call to renewal. San Francisco, CA: Jossey-Bass.

Scharmer, C. O. (2009). Theory U: Leading from the future as it emerges. San Francisco, CA: Berrett-Koehler.

Schein, E. H. (2004). Organizational culture and leadership. San Francisco, CA: Jossey-Bass.

Senge, P. (1990). The fifth discipline: The art and practice of the learning organization. New York, NY: Currency Doubleday.

Senge, P. M., Scharmer, O. C., Jaworski, J., \& Flowers, B. S. (2004). Awakening faith in an alternative future. Reflections: The SoL Journal on Knowledge, Learning and Change, 5(7), 1-17.
Torbert, B., \& Associates. (2004). Action inquiry: The secret of timely and transformative leadership. San Francisco, CA: Berrett-Koehler.

Wenger, E. (1998). Communities of practice: Learning, meaning and identity. Cambridge, MA: Cambridge University Press.

Yorks, 1., \& Kasl, E. (2002). Toward a theory and practice for whole person learning: Reconceptualising experience and the role of affect. Adult Education Quarterly, 52(3), 176-192.

\section{Acknowledgements}

This research was reviewed and approved by Camosun College's Research Ethics Board.

\section{Biography}

Martha McAlister, BSW, Med, $\mathrm{PhD}$, is an instructor and program leader, who has been a college educator for the past decade, teaching in a diploma called Community, Family, and Child Studies. More recently, she has also been working as a CoP Coordinator in the Teaching and Learning Centre, helping to create a culture of Communities of Practice at Camosun College. Before a career in higher education, Martha worked as a social worker and an educator in a wide range of settings. A core curiosity that has driven her throughout her adult life is the question of how to create scaffolding for our highest potential, balancing support and challenge, and using minimum structure for maximum emergence. 